\title{
Logit model application for valuating intangible benefits from the afforested areas
}

\author{
Girish Chandra \\ Division of Forestry Statistics, Indian Council of Forestry Research and Education, \\ Dehradun, India \\ Avinash Jain \\ Tropical Forest Research Institute, Jabalpur, India, and \\ Sanjay Kumar \\ Ministry of Statistics and Program Implementation, New Delhi, India
}

Logit model application

Abstract

Purpose - The estimation of market value of intangible benefits of afforestation has always been a challenging task, and the contingent valuation method is a popular method used in environmental assessment. The NTPC set up a coal-based power plant in Korba, India and planted 1.6 million trees on $19 \%$ of the project area.

Design/methodology/approach - The individual's mean and median willingness to pay (WTP) for four intangible benefits, namely, pollution control (PC), improvement in underground water level (IUGWL), soil conservation and remediation (SCR) in addition to total WTP from the afforestation program of NTPC were estimated using a customized procedure for logit model based upon respondent's age, education, occupation, income and bid amount asked to pay. Stratified multistage random sampling has been used to select the respondents.

Findings - The procedure increases the number of respondents who are willing to pay as compared to conventional CVM. The finding of the study shows that the highest WTP was observed for PC (Rs. 462.84 per month per household) followed by SCR and IUGWL, whereas for total WTP it was Rs. 972.60.

Originality/value - The proposed customized procedure and the results thereof would be useful in improving the WTP estimates for other similar studies in order to conserve the environment.

Keywords Contingent valuation method, Utility function, Logit model, Willingness to pay, $t$-Statistic

Paper type Research paper

\section{Introduction}

The forest ecosystem is a vital element to sustain the life support system and generate a wide variety of use values. The most important of which are timber and nontimber, recreation, wildlife habitat and watershed services. Over the last several decades, researchers have developed and refined a number of methods for estimating market value of intangible socioeconomic benefits arisen from the afforestation and natural habitat. Among the stated

(c) Girish Chandra, Avinash Jain and Sanjay Kumar. Published in Forestry Economics Review. Published by Emerald Publishing Limited. This article is published under the Creative Commons Attribution (CC BY 4.0) licence. Anyone may reproduce, distribute, translate and create derivative works of this article (for both commercial and non-commercial purposes), subject to full attribution to the original publication and authors. The full terms of this licence may be seen at http://creativecommons.org/licences/by/4.0/ legalcode

Ethics approval and consent to participate: Not applicable.

Consent for publication: Not applicable.

Availability of data and materials: The datasets used and/or analyzed during the current study are available from the corresponding author on reasonable request.

Competing interests: All authors declare that they have no competing interests.

The authors would like to express their deep sense of appreciation to NTPC Korba for providing financial support to conduct this study.

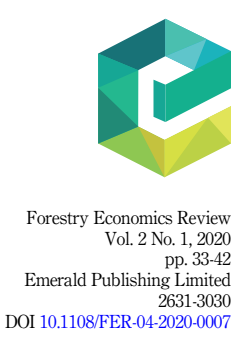


FER

2,1

34

preference methods, the contingent valuation method (CVM) is the most widely used in environmental assessment of developmental and infrastructural projects. The CVM is a simple, flexible, nonmarket valuation method which was originally proposed by Ciriacy Wantrup (1947) as a method for valuation of "extra market benefits" of nonmarket goods. The CVM involves directly asking people, in a survey, how much they would be willing to pay for the conservation of natural environmental services for possible future use or conversely, how much compensation they would demand to be induced to give up their access. It is called "contingent" valuation because people are asked to state their willingness to pay, contingent on a specific hypothetical scenario and description of the environmental service. The first practical application of CVM was given by Davis (1963) for estimating the value of hunters and tourists placed on a particular wilderness area. Haefele et al. (1991) estimated total value of forest quality in high elevation spruce-fir forest in southern Appalachian Mountains from exotic insects and air pollution. Pak and Turker (2006) estimated recreational use value of forest resources of Kayabasi forest of Turkey and compared with travel cost method. Madureira et al. (2011) and Majumdar et al. (2011) assessed forest management strategies in urban forests. Jain et al. (2017) assessed some intangible benefits arising from NTPC, Dadri through the use of logit model. Other useful, but rarely used methods, for financial and economic analysis of forestry sector are travel cost, tourism expenditure, conjoint analysis, etc.

People are willing to pay for nonuse or passive use of environmental benefits; however, these benefits are likely to be implicitly treated as zero unless their value is somehow estimated. Because people do not reveal their willingness to pay (WTP) for them through their purchases or by their behavior, the only option for estimating a value is by adopting questionnaire approach. Three questionnaire approaches are commonly used as follows: (1) Open-ended approach (respondent is asked to name the amount) (2) close-ended approach (respondent is asked whether or not he/she would pay a single specified amount) and (3) sequential bids approach (uses first close-ended approach, then repeats this approach using a higher or lower amount depending on the initial response, and so on, until the decision on final amount is taken). Out of these three, the close-ended approach is preferred because it generates a scenario similar to that encountered by consumers in their usual market transactions (Cameron and Michelle, 1986). The present study discusses a new approach based upon the open-ended approach.

The diversion of forest land for facilitating developmental activities like construction of power and irrigation projects, roads, railways, mining, etc. has become the order of day. In compliance with various guidelines and acts on forest conservation, usually the conditions of compensatory afforestation or deposition of funds for raising compensatory afforestation in lieu of diversion of forest land is imposed. The National Thermal Power Corporation (NTPC) set up a power plant in Korba, India and raised a massive plantation around the project site. The project started in 1979, and since then the afforestation activities, one of the integral parts of the project activity, are going on in its stations. The activities like green belt development, raising plantations, development of parks, green areas, horticulture activities, development of medicinal gardens etc., are undertaken by NTPC in coordination with state forest department and local bodies involving displaced families and local population. Most of the area was the degraded land before the establishment of this project. The seedlings have been planted on NTPC-acquired land and Chhattisgarh government land along the road by different agencies including NTPC Korba, Madhya Pradesh State Forest Development Corporation (before Chhattisgarh parted as individual state), Chhattisgarh State Forest Development Corporation, Bhu.-V Society, TERI and Indus.

The objective of the present study is the valuation of important intangible socioeconomic benefits arising through this afforestation. Four intangible benefits namely pollution control (PC), improvement in underground water level (IUGWL), soil conservation and remediation (SCR) and total WTP (which comprises all these three benefits) were identified for the study 
during a preliminary survey. $\mathrm{PC}$ was mainly concerned with $\mathrm{CO}_{2}$, $\mathrm{SOx}$ and $\mathrm{NOx}$, which are emitted to the atmosphere in huge amounts from chimneys of thermal power plant due to the process of burning of inferior quality coal. IUGWL and SCR were identified for the study because the livelihood of most of the local people depends on farming and these two benefits are directly related to agriculture production. People were ready to pay some amount of their income for the conservation of these environmental resources for their livelihood and income generation as well as for their future generations.

The sampling methodology, customized logit procedure based upon the empirical model (utility difference model) to estimate the people's expected mean and median WTP, has been discussed in Section 2. The Section 3 deals with the results, and finally the study has been concluded in Section 4.

\section{Methods}

\subsection{Study area}

The NTPC, largest energy conglomerate in India has set up a coal-based power plant at Jamanipali at Korba district in the Indian state of Chhattisgarh having capacity of 2,600 MW. The plant has been established on acquired agricultural land originally belonging to nearby villagers. There are a total of $1.6 \mathrm{mn}$ trees planted till March 2008 in and around this plant on approximately $19 \%$ of the project area. These plantations have been raised on soil and fly ash mound by NTPC with the help of local people, which mostly consist of tree species like Cassia siamea, Delonixregia, Azadirachtaindica,Bombaxceiba, Pongamiapinnata, Ailanthus excels, Acacia auriculiformis, Dalbergia sisso and, Albiziaprocera and Phyllanthusemblica. The villagers of nearby villages collect fuelwood and fodder and are directly or indirectly connected to these tree plantations starting from raising them till collection of nonwood forest produce. Although the plantations are owned by NTPC, the tangible and intangible benefits are extracted by the surrounding local people. Kusmundha and Gevra mines are the major source of coal for the plant. The plant is located on $22.3858^{\circ} \mathrm{N}$ latitude and $82.6816^{\circ} \mathrm{E}$ longitude.

\subsection{Sampling methodology}

The study area comprises a total area of $10 \mathrm{~km}$ radius from the center of the plant and was divided into two zones, inner and outer, each having a radius of $5 \mathrm{~km}$. This criterion was chosen to get a group of true representative of respondents from both the zones. The procedure developed for selecting zone-wise villages/households/members is detailed below:

(1) Prepared the alphabetical list of villages for each zone using the information from important secondary sources namely, Census of India (2011), records of Zila Panchayat and Gram Sabha and the literature available with NTPC in the prescribed format.

(2) Selected 10 villages from each zone using simple random sampling without replacement.

(3) Prepared a frame of 30 households (10 from large, 10 from medium and 10 from small household sizes) in each selected village using the secondary information/data available.

(4) Selected six households randomly from each of the 10 households mentioned above which resulted in a total of 18 selected households from each selected village. If there were less than six households in a particular category, then remaining were selected from the next succeeding category.

(5) The procedure resulted in selection of total 360 households in 20 selected villages in inner and outer zones. 
FER

2,1

36

(6) Visited each and every household for personal interview and identified the key respondent from each household (who happened to be either head of the household or most educated member).

All the selected respondents were invited for a one-day scheduled workshop for giving them further in-depth knowledge about the four intangible benefits due to plantations and for personal interaction for resolution of any query.

\subsection{Customized procedure for estimating WTP}

In the common procedure for observing WTP (Loomis et al., 1998), the respondents are generally asked the following question: Would you really be prepared to pay, say Rs. " $A$ " (bid amount) for a particular intangible benefit? In the response, we receive "yes" or "no". Here, in such procedures, two kinds of response error may creep. First, the yes/no responses may come without any "deep thinking" by the respondents. It may be due to lack of awareness about the importance and future benefits of the intangible benefit. This type of error can be minimized by deep interaction among individuals and experts and inclusion of the special type of hypothetical questions in the questionnaires as mentioned by Loomis et al. (1998). Second, the respondent is in dilemma in responding to the question, keeping the quantum of bid amount in view. In such a situation, the respondent is indifferent in opting the choice of "yes" and "no". Had the amount been a little bit lower than the proposed one, the respondent would have thought in responding "yes". This may significantly affect the results. To overcome this type of error, we propose an indirect approach for taking decision on "yes" or "no" after calculating the revised threshold bid amount $A$.

In the proposed approach, the respondent is asked directly that how much monthly amount he/she is willing to pay for a given intangible benefit, and the average bid amount is calculated for each and every intangible benefit. Instead of taking an arbitrary bid amount, we have taken the average monthly amount as the bid amount for a particular intangible benefit. The average bid amount so arrived for each of intangible benefits may be seen in Table 2. The respondents are made convinced to pay this amount in real sense if asked by the NTPC or other governmental agency. Suppose, there are $m$ intangible benefits to be studied for $n$ respondents and $a_{i j}$ denotes the amount which the $j$ th respondent would like to pay for the $i t h$ benefit. The WTP component matrix can be written as follows:

$$
W=\left[\begin{array}{cccccc}
a_{11} & a_{12} & \cdots & a_{1 j} & \cdots & a_{1 n} \\
a_{21} & a_{22} & \cdots & a_{2 j} & \cdots & a_{2 n} \\
\vdots & \vdots & \vdots & \vdots & \vdots & \vdots \\
a_{i 1} & a_{i 2} & \cdots & a_{i j} & \cdots & a_{i n} \\
\vdots & \vdots & \vdots & \vdots & \vdots & \vdots \\
a_{m 1} & a_{m 2} & \cdots & a_{m j} & \cdots & a_{m n}
\end{array}\right]_{m \times n}
$$

Suppose $A_{i}=\frac{1}{n} \sum_{j=1}^{n} a_{i j}$ is the average amount (proposed bid amount) for the $i$ th intangible benefit. In the usual procedure, a respondent is considered willing to accept the bid amount if $a_{i j} \geq A_{i}$ and all the respondent for which $a_{i j}<A_{i}$, are considered not willing to accept the bid amount. In such a procedure, the decision of rejecting bid amount on the basis of criterion $a_{i j}<A_{i}$ doesn't seem appropriate for those $a_{i j}$ 's which are not too distant from $A_{i}$. At least the borderline cases could have been treated "yes".

In the proposed customized procedure, a respondent is considered willing to accept the bid amount either if

(i) $a_{i j} \geq A_{i}$ or (ii) $a_{i j}<A_{i}$ and accept $H_{0}: a_{i j}=A_{i}$ vs $H_{1}: a_{i j}<A_{i}$

The null hypothesis $H_{0}$ is tested using $t$-test at $(n-1)$ degrees of freedom and at given level of significance ( $5 \%$ in our case). In other words, the bid amount is modified to $A_{i}-t_{n-1,0.05}$. This 
customized approach seems to be more precise as it includes those respondents into consideration for which the difference between WTP amount and the average bid amount is not statistically significant.

Now, the approach of Hanemann (1984) for estimating mean and median WTP through utility difference model was used.

The indirect utility function, in our case, is defined by a function in which the individual receives utility from income (I) and percentage of gain/reduction to the corresponding intangible benefit due to plantation. The model can be written as follows:

$$
U=f(j, I ; S)+\varepsilon_{j}
$$

where $S$ denotes some socioeconomic characteristics that are influenced by personal taste. The value $j$ is dichotomous and is written as follows:

$$
j=\left\{\begin{array}{l}
1, \text { represents the respondent must pay the bid amount } A \\
0, \text { represents respondent would not pay } A \text { or no response received }
\end{array}\right.
$$

Using Eqns (1) and (2), the utility function can be written as follows:

$$
U=\left\{\begin{array}{l}
f(1, I-A ; S)+\varepsilon_{1}, \text { if } j=1 \\
f(0, I ; S)+\varepsilon_{0}, \text { if } j=0
\end{array}\right.
$$

where, $\varepsilon_{1}$ and $\varepsilon_{0}$ are independent and identical random variables with zero means and $I-A$ represents balance income after the bid amount Rs. " $A$ " to be paid. In terms of utility gain, the respondent will pay the amount " $A$ " if the utility difference $\Delta f=f(1, I-A ; S)-f(0, I ; S)+\varepsilon_{1}-\varepsilon_{0}$ is positive. For calculation point of view, it is assumed that $\Delta f$ is logistically distributed. Therefore, the corresponding logit model for any prescribed intangible benefit can be written as follows:

\begin{tabular}{ll} 
Age & Age in years (scale variable) \\
\hline $\begin{array}{l}\text { Education } \\
\text { Occupation }\end{array}$ & $\begin{array}{l}\text { Education of respondents in years (scale variable) } \\
\text { Dummy variable on whether a respondent has government job, private company job, reputed } \\
\text { business etc. (excluding student/farmer/laborer/ housewife) or not. 1 denotes for yes and 0 for no } \\
\text { (categorical variable) }\end{array}$ \\
$\begin{array}{l}\text { Income } \\
\text { Average monthly income in rupees (scale variable) } \\
\text { The bid amount asked to pay (scale variable) }\end{array}$
\end{tabular}

Table 1. Definition of variables

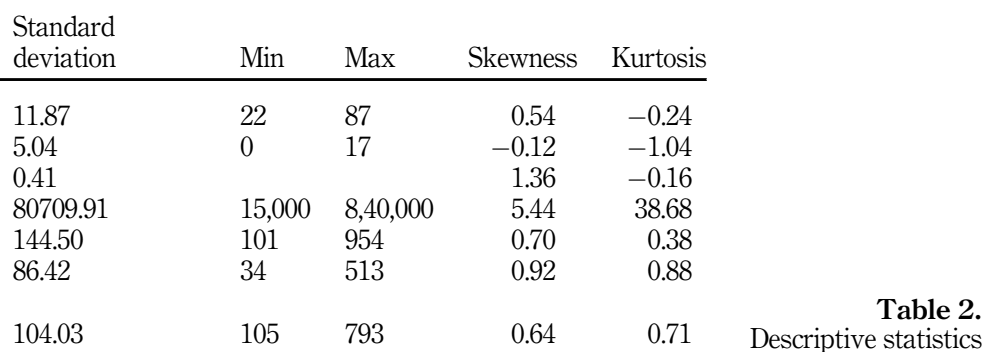

\begin{tabular}{|c|c|c|c|c|c|c|c|}
\hline Variables & Mean & $\begin{array}{l}\text { Standard } \\
\text { deviation }\end{array}$ & Min & Max & Skewness & Kurtosis & \\
\hline Age (years) & 43.70 & 11.87 & 22 & 87 & 0.54 & -0.24 & \\
\hline Education (in years) & 7.48 & 5.04 & 0 & 17 & -0.12 & -1.04 & \\
\hline Occupation (mode) & Cat “0” & 0.41 & & & 1.36 & -0.16 & \\
\hline Income (yearly in rupees) & 58523.33 & 80709.91 & 15,000 & $8,40,000$ & 5.44 & 38.68 & \\
\hline WTP (PC) (monthly in rupees) & 464.54 & 144.50 & 101 & 954 & 0.70 & 0.38 & \\
\hline $\begin{array}{l}\text { WTP (IUGWL) (monthly in } \\
\text { rupees) }\end{array}$ & 178.94 & 86.42 & 34 & 513 & 0.92 & 0.88 & \\
\hline WTP (SCR) (monthly in rupees) & 337.21 & 104.03 & 105 & 793 & 0.64 & 0.71 & Descriptive statistics \\
\hline $\begin{array}{l}\text { WTP (total) (monthly in } \\
\text { rupees) }\end{array}$ & 980.69 & 252.80 & 707 & 1,797 & 0.48 & -0.70 & $\begin{array}{r}\text { for socioeconomic } \\
\text { (explanatory) variables }\end{array}$ \\
\hline
\end{tabular}

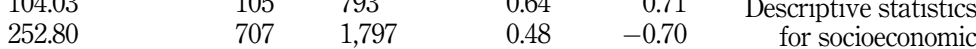
(explanatory) variables 
FER

2,1

$$
\operatorname{Logit}\left(\pi_{i}\right)=\log \left(\frac{\pi_{i}}{1-\pi_{i}}\right)=\beta_{0}+\beta_{1} A+\beta_{2} Z_{1}+\ldots \beta_{n} Z_{n}
$$

where, $\pi_{i}=\operatorname{Pr}(Y e s)=(1+\exp (-\Delta f))^{-1}$ and the $Z$ variables are the socioeconomic predictors (main variables and/or their interactions) taken for the study. The predictors taken for this study are the same as taken in the study of Jain et al. (2017) (Table 1).

In case of unknown $\Delta f, \pi_{i}=\frac{m_{i}}{m}$, where $m_{i}$ and $m-m_{i}$ denote the number of respondents willing and not willing to pay the amount Rs."A" respectively.

Recognizing that WTP is a random variable with a cumulative distribution function $G(A)$, it can be written as follows:

$$
\mathrm{WTP}=\int_{0}^{\infty}(1-G(A)) \mathrm{d} A
$$

The formula proposed by Hanemann (1989, p. 1059) can be used for calculating the mean and median WTP for each intangible benefit as follows:

$$
\begin{gathered}
\text { Mean WTP }=\frac{\log (1+\exp (\alpha))}{B} \\
\text { Median WTP }=\frac{\alpha}{B}
\end{gathered}
$$

where, $\alpha=$ intercept + sum of the product of the coefficient and corresponding mean values of the predictors excluding the bid variable and $B$ is the absolute value of the bid coefficient.

\section{Results}

\subsection{Data collection and descriptive statistics}

A total of 300 respondents were willing to express their views on plantation done by the NTPC. They all were well aware of intangible benefits and CVM as they have deeply gone through the literature provided to them and the presentations given by the experts. The respondent format (with some relevant modification) as suggested by NOAA panel (Arrow et al.,1993) was used for the purpose. The columns pertaining to WTP envisage the question through the open-ended approach as follows: What is your maximum WTP for each benefit? The average WTP for the four intangible benefits along with the socioeconomic characteristics are shown in Table 2.

The above table shows that the average age of respondents is 43.70 years, average number of years in education is 7.48 years with average annual household income of Rs. 58,523.33. The observed total WTP per household is Rs. 980.69 (20.11\% of their income) for the plantations raised by NTPC Korba, out of which the contribution towards PC was found highest (Rs. 464.54 per month) followed by SCR (Rs. 337.27 per month) and IUGWL (Rs. 178.94 per month). The improved estimates (we call it expected estimates) and pattern of these benefits can be seen in subsequent section in which the improved WTP is calculated using logit model. Logit model is opted because it maintained the stability and compatibility of theoretical constraints, statistical efficiency and congregate ability (White and Lovett, 1999).

The Table 3 shows the results of the customized procedure as discussed in the preceding section. The average bid amount $A$ is shown in the column 2, and the revised bid amount calculated using $t$-test at $5 \%$ level of significance is shown in column 3 . The maximum increase in "yes" response is received for IUGWL (6.33\%) followed by PC (5.33\%) and SCR $(2.33 \%)$ with no increase in the total WTP. The corresponding $t$-value and $p$-value of all the benefits are shown in column 6 . 
3.2 Estimation and analysis of WTP responses

We began with the logistic regression model given in Eqn (4) in which the selected variables used are given in the Table 1 . The results of logit model for the estimated coefficients, effect of predictors on the response variable based on maximum likelihood estimation is presented in Table 4. In all logit regressions, the bid variable is itself negative with higher value of Wald statistic, indicating that as soon as we increase the proposed amount of bid and ask to pay, fewer respondents would like to pay. This proves the internal validity of CVM responses. The positive coefficient for PC in age, education and occupation shows that the older, highly educated people and the people other than student, laborer and small businessman are interested to pay for PC only and not interested much for IUGWL and SCR. This means that
Logit model application

\begin{tabular}{|c|c|c|c|c|c|c|}
\hline $\begin{array}{l}\text { Intangible } \\
\text { benefits }\end{array}$ & $\begin{array}{l}\text { Average bid } \\
\text { amount } \\
\text { (standard } \\
\text { error) }\end{array}$ & $\begin{array}{l}\text { Revised bid } \\
\text { amount from the } \\
\text { customized } \\
\text { procedure }\end{array}$ & $\begin{array}{l}\% \text { increase in the } \\
\text { respondents } \\
\text { willing to pay }\end{array}$ & $\begin{array}{l}\text { Total \% of } \\
\text { respondents } \\
\text { willing to pay }\end{array}$ & $\begin{array}{l}t \text {-value } \\
(p \text { value) }\end{array}$ & \\
\hline $\mathrm{PC}$ & $464.54(8.34)$ & 448 & 5.33 & 51.67 & \multirow{4}{*}{$\begin{array}{l}1.984977 \\
(0.0481) \\
1.984500 \\
(0.0481) \\
2.031077 \\
(0.0431) \\
2.034436 \\
(0.0428)\end{array}$} & \multirow{4}{*}{$\begin{array}{r}\text { Table 3. } \\
\text { Test of means against } \\
\text { bid amount } A \text { and \% of } \\
\text { respondents willing } \\
\text { to pay }\end{array}$} \\
\hline IUGWL & $178.94(4.99)$ & 169 & 6.33 & 46.33 & & \\
\hline SCR & 337.27 (6.01) & 325 & 2.33 & 52.67 & & \\
\hline Total & 980.69 (14.60) & 951 & 0 & 54.00 & & \\
\hline
\end{tabular}

\begin{tabular}{|c|c|c|c|c|c|c|}
\hline & & $\mathrm{PC}$ & IUGWL & SCR & Total & \\
\hline \multirow[t]{3}{*}{ Intercept } & Coefficient (SE) & 712.20 & 455.2474 & 495.7151 & 126.0794 & \\
\hline & & (249.9286) & (162.4889) & (219.2946) & (197.4521) & \\
\hline & $\begin{array}{l}\text { Wald statistic } \\
\text { ( } p \text {-value) }\end{array}$ & $\begin{array}{c}8.1203 \\
(0.004377)\end{array}$ & $\begin{array}{r}7.849599 \\
(0.005083)\end{array}$ & $\begin{array}{l}5.109854 \\
(0.02379)\end{array}$ & $\begin{array}{c}0.407722 \\
(0.523128)\end{array}$ & \\
\hline \multirow[t]{4}{*}{ Age } & Coefficient (SE) & 0.019604 & -0.41667 & -0.11528 & -0.02426 & \\
\hline & & $(0.295401)$ & $(0.357672)$ & $(0.261916)$ & (1.357758) & \\
\hline & Wald statistic & 0.004404 & 1.357078 & 0.193725 & 0.000319 & \\
\hline & ( $p$-value) & $(0.947087)$ & $(0.244044)$ & $(0.659834)$ & $(0.985743)$ & \\
\hline \multirow[t]{3}{*}{ Education } & Coefficient (SE) & 0.387439 & -0.35131 & -0.01228 & -0.16217 & \\
\hline & & (0.476945) & (0.804405) & $(0.802317)$ & (3.612237) & \\
\hline & $\begin{array}{l}\text { Wald statistic } \\
\text { ( } \text {-value) }\end{array}$ & $\begin{array}{r}0.659888 \\
(0.416599)\end{array}$ & $\begin{array}{c}0.190732 \\
(0.662308)\end{array}$ & $\begin{array}{c}0.000234 \\
(0.987789)\end{array}$ & $\begin{array}{c}0.002015 \\
(0.964192)\end{array}$ & \\
\hline \multirow[t]{3}{*}{ Occupation } & Coefficient (SE) & 1.606168 & -0.70147 & -1.69738 & -5.03487 & \\
\hline & Wald statistic & $\begin{array}{c}(2.294015) \\
0.490218\end{array}$ & $\begin{array}{c}(2.453981) \\
0.081711\end{array}$ & $\begin{array}{c}(3.493304) \\
0.236095\end{array}$ & $\begin{array}{c}(17.20618) \\
0.085626\end{array}$ & \\
\hline & ( $p$-value) & $(0.48383)$ & $(0.774992)$ & $(0.627041)$ & $(0.769813)$ & \\
\hline \multirow[t]{4}{*}{ Income } & Coefficient (SE) & -0.00188 & -0.00126 & 0.001463 & 0.000408 & \\
\hline & & $(0.002359)$ & (0.001605) & $(0.001097)$ & $(0.002556)$ & \\
\hline & Wald statistic & 0.635722 & 0.613979 & 1.778983 & 0.025457 & \\
\hline & ( $p$-value $)$ & $(0.425264)$ & (0.433293) & $(0.182274)$ & $(0.873234)$ & \\
\hline \multirow[t]{4}{*}{ Bid } & Coefficient (SE) & -1.52992 & -2.53289 & -1.52838 & -0.12778 & \\
\hline & & $(0.535361)$ & $(0.898375)$ & $(0.676032)$ & $(0.166254)$ & \\
\hline & Wald statistic & 8.166606 & 7.949076 & 5.111256 & 0.59073 & \\
\hline & ( $p$-value) & $(0.004267)$ & $(0.004811)$ & $(0.023771)$ & $(0.442137)$ & Table 4 \\
\hline \multirow{2}{*}{\multicolumn{2}{|c|}{$\begin{array}{l}-2 \log \text { likelihood } \\
\text { Cox and Snell } R^{2}\end{array}$}} & 0.5845 & 0.5942 & 0.2840 & 0.0054 & Estimated coefficients \\
\hline & & 0.750 & 0.749 & 0.749 & 0.748 & using logit model \\
\hline
\end{tabular}


FER 2,1

40

the older and highly educated people are more worried of the increasing pollution from the project and are willing to pay for conservation of the environment. The reasons behind it may be that they are more concerned about the possible adverse impact of pollution on their forthcoming generations. The data reveal that most of the high income people are also involved in the agriculture, and therefore they are more interested in SCR (due to the positive coefficient of income in SCR). If we look at total WTP, only the income has positive value, which indicates that the most decisive variable for accepting the proposed bid amount is income. It is an indication that respondents identify themselves according to their income status rather than the occupation.

Furthermore, Cox and Snell coefficients of determination for each of the benefits were calculated. These coefficients suggest that the predictors of the model explained the response variable very well.

The expected mean and median WTP using the Eqns (6) and (7) using the principle of maximum likelihood were calculated (Table 5). Surprisingly, the mean and median WTP for each of the benefits were found same.

The WTP for PC is found the highest, followed by IUGWL and SCR. The reason for high WTP for PC may be that the surrounding of the plant is much affected by the pollution generated by the plant and airborne diseases. It is a good indication that the people are ready to pay about $20 \%$ of their income for the conservation of plants raised by NTPC.

$\chi^{2}$ test to check the significant difference between the observed WTP (Table 2) and expected WTP (Table 5) for each of the benefits shows that all the benefits significantly differ at $5 \%$ level (Table 6). Highest difference (Rs. 11.82) between observed and expected WTP was found for IUGWL among all the benefits.

For the purpose of statistical analysis and mathematical calculations, STATISTICA software was used. Iteration method with maximum 11 iterations was used for logit model calculation in this software. The Cox and Snell $R^{2}$ have been calculated using SPSS software.

\section{Discussion}

It was observed that the PC is the largest component for WTP. The WTP for PC is not much depending positively on the explanatory variable income. It is a clear indication that all the local people are concerned with pollution irrespective of their income. The second largest component of WTP, IUGWL shows that the perception about to increase in groundwater level became the trend of traditional approach which came through their earlier generations. The total WTP much negatively affected by the respondents having high occupation means

Table 5.

Monthly mean and median WTP (in Indian Rs.)

\begin{tabular}{lllll}
\hline & \multicolumn{3}{c}{ Benefits } & \\
& PC & IUGWL & SCR & Total \\
\hline$\alpha$ & 708.11 & 427.24 & 497.32 & 124.28 \\
$B$ & 1.53 & 2.53 & 1.53 & 0.13 \\
Expected mean monthly WTP & 462.84 & 168.68 & 325.39 & 972.60 \\
Expected median monthly WTP & 462.84 & \multirow{2}{*}{168.68} & 325.39 & 972.60 \\
\hline
\end{tabular}

\begin{tabular}{|c|c|c|c|c|c|}
\hline \multirow{3}{*}{$\begin{array}{l}\text { Table } 6 \text {. } \\
\text { Chi-squared test for the } \\
\text { observed vs } \\
\text { expected WTP }\end{array}$} & Benefits & PC & IUGWL & $\mathrm{SCR}$ & Total \\
\hline & $\chi^{2}$ value at $299 \mathrm{df}$ & 13491.1 & 13425.75 & 10072.95 & 19666.95 \\
\hline & $p$-value & $<0.05$ & $<0.05$ & $<0.05$ & $<0.05$ \\
\hline
\end{tabular}


the occupation is higher, the lower their total WTP and the less their tendency to conserve the environment. Similar results were found by Tao et al. (2012) and Khosravi and Sabouhi (2011).

The total observed WTP is simply the sum of WTPs of all the components, which is not true for the case of expected WTP. The reason behind that is the likelihood function of sum of explanatory variables is not equal to the sum of their individual likelihood functions. The percentage of respondents willing to pay the prescribed bid amount may vary from $100 \%$ to $0 \%$ depending upon the amount of bid prescribed for the study. The customized procedure discussed in this paper is an additional advantage to correct this percentage amount and increase the reliability of the results. This customized procedure increases "yes" respondents with maximum increase in IUGWL namely $6.33 \%$. The decision on this prescribed amount is a big issue for the results which may affect expected WTP amount, however, the order statistics for the components under study may not differ by changing the amount. If the percentage of "yes" respondents is very low, say less than $20 \%$, the bid amount may be decreased considerably from the average amount so as to increase this percentage value for the effective conclusion.

In the lines of Amiri et al. (2015), one may believe that it is required to educate the local population about proper harvesting methods and management of the important tree plantations by trained and field experts. Therefore, the proper management and policies together with necessary financial and administrative support, an opportunity for the provincial economy and an increase in employment may be enhanced. Here, we would also like to mention the exchange rate between Indian rupees and US dollars at the time of submission of this article is Rs. $1=0.014$ USD.

\section{Conclusion}

The proposed customized procedure for determining WTP is found to be suitable to reduce the response error and to calculate revised threshold bid value during the survey. The logit model was successfully used for estimating an individual's WTP on community plantations in and around one of the major power projects in India. It shows the understanding and preference of local people on importance of plantations raised by NTPC. Such an understanding has gradually developed as the local people began to realize the extent of plantations (particularly broad-leaved species) in their area and hence the need for its conservation. The results of this study may provide a great help to the policy makers on raising plantations of broad-leaved tree species before installation of the power or other similar projects in the state or other parts of the country.

\section{References}

Amiri, N., Emadian, S.F., Fallah, A., Adeli, K. and Amirnejad, H. (2015), "Estimation of conservation value of myrtle (Myrtuscommunis) using a contingent valuation method: a case study in a Dooreh forest area”, Lorestan Province, Iran. For Ecosys, Vol. 2 No. 30, pp. 1-11.

Arrow, K., Solow, R., Portney, P.R., Leamer, E.E., Radner, R. and Schuman, H. (1993), "Report of the NOAA panel on contingent valuation", Federal Register, Vol. 58 No. 10, pp. 4601-4614.

Cameron, T.A. and Michelle, D.J. (1986), Efficient Estimation Methods for the use with 'Closed-Ended' Contingent Valuation Survey Data, Discussion paper \#04, Department of Economics, University of California, Los Angeles.

Ciriacy-Wantrup, S.V. (1947), "Capital returns from soil-conservation practices”, Journal of Farm Economics, Vol. 29, pp. 1181-1196.

Davis, R.K. (1963), The Value of Outdoor Recreation: An Economic Study of the maine Woods, Dissertation, Harvard University, Cambridge, MA. 
FER

2,1

Haefele, M.A., Kramer, R.A. and Holmes, T.P. (1991), "Estimating the total value of forest quality in high elevation forests", Proceedings: National Conference on the Economic Value of Wilderness, May 9-11, 1991, Jackson Hole WY.

Hanemann, W.M. (1989), "Welfare evaluations in contingent valuation experiments with discrete response Data: Reply”, American Journal of Agriculture Economics, Vol. 71, pp. 1057-1061.

Hanemann, W.M. (1984), "Welfare evaluations in contingent valuation experiments with discrete responses", American Journal of Agriculture Economics, Vol. 66, pp. 332-341.

Jain, A., Chandra, G. and Nautiyal, R. (2017), "Valuating intangible benefits from afforested areas: a case study in India”, EconomíaAgraria Y RecursosNaturales, Vol. 17 No. 1, pp. 89-100.

Khosravi, M. and Sabouhi, M. (2011), "Estimating conservation value of tamarisk in Fahliyan river bank using by contingent valuation method", Journal of Environmental Sciences, Vol. 4, pp. $73-82$.

Loomis, J., Peterson, G., Champ, P., Brown, T. and Lucero, B. (1998), "Paired comparison estimates of willingness to accept versus contingent valuation estimates of willingness to pay", Journal of Economics Behavior and Organization, Vol. 35, pp. 501-515.

Madureira, L., Nunes, L.C., Borges, J.G. and Falcao, A.O. (2011), “Assessing forest management strategies using a contingent valuation approach and advanced visualization techniques : a Portuguese case study", Journal of Forest Economics, Vol. 17, pp. 300-414.

Majumdar, S., Deng, J., Zhang, Y. and Pierskalla, C. (2011), "Using contingent valuation to estimate the willingness of tourists to pay for urban forests : a study in Savannah. Georgia", Urb For Urb Green, Vol. 10, pp. 275-280.

Pak, M. and Turker, M.F. (2006), "Estimation of recreational use value of forest resources by using individual travel cost and contingent valuation methods (Kayabasi forest recreation site sample)", Journal of Applied Sciences, Vol. 6 No. 1, pp. 1-5.

Tao, Z., Yan, H. and Zhan, J. (2012), "Economic valuation of forest ecosystem services in Heshui watershed using contingent valuation method", Procedia Environmental Sciences, Vol. 13, pp. 2445-2450.

White, P.C.L. and Lovett, J.C. (1999), "Public preferences and willingness to pay for nature conservation in the north york moors national park UK", Journal of Environmental Management, Vol. 55, pp. 1-13.

\section{Corresponding author}

Girish Chandra can be contacted at: gchandra23@yahoo.com

For instructions on how to order reprints of this article, please visit our website:

www.emeraldgrouppublishing.com/licensing/reprints.htm

Or contact us for further details: permissions@emeraldinsight.com 